\title{
Imaging Findings Related to the Valsalva Maneuver in Head and Neck Radiology
}

\author{
(D) A.A. Madhavan, (D) C.M. Carr, (D) M.L. Carlson, and (D).I. Lane
}

\section{ABSTRACT}

SUMMARY: Forced exhalation against a closed glottis, known as the Valsalva maneuver, is an important clinical diagnostic and therapeutic tool due to its physiologic effects. Several unique conditions and anatomic changes can occur with repetitive or acute changes in pressure from the Valsalva maneuver. We will discuss and review various pertinent head and neck imaging cases with findings resulting from induced pressure gradients, including the Valsalva maneuver. Additionally, we will demonstrate the diagnostic utility of the Valsalva maneuver in head and neck radiology.

$\mathrm{T}$ he Valsalva maneuver, defined as forceful exhalation against a closed glottis, has multiple physiologic effects. The maneuver can be divided into 4 major phases of physiologic response: First, the initial exhalation increases intrathoracic pressure and forces blood into the left atrium. Second, the high intrathoracic pressure causes decreased systemic venous return. Next, as intrathoracic pressure returns to normal, cardiac output oscillates due to mixed effects from aortic dilation and improving venous return. Finally, once thoracic pressure normalizes, cardiac output stabilizes and sometimes transiently increases above baseline. ${ }^{1}$ Throughout this process, the maneuver also results in opening the Eustachian tube, partially due to contraction of the tensor veli palatini muscle. While the complex effects of the Valsalva maneuver have multiple clinical applications, the increase in intrathoracic pressure, decreased systemic venous return, and opening of the Eustachian tube are particularly relevant to the following discussion (Table 1). A wide spectrum of head and neck imaging findings has been attributed to the Valsalva maneuver or other similar induced-pressure gradients. Knowledge and recognition of these findings can be especially valuable to the neuroradiologist.

Received June 13, 2019; accepted after revision September 23.

From the Departments of Radiology (A.A.M., C.M.C., J.I.L.) and OtolaryngologyHead and Neck Surgery (M.L.C.), Mayo Clinic School of Medicine, Rochester, Minnesota.

Internal departmental funding was used without commercial sponsorship or support.

Paper previously presented at: Annual Meeting of the American Society of Head and Neck Radiology, September 26-20, 2018; Savannah, Georgia.

Please address correspondence to Ajay A. Madhavan, MD, Department of Radiology, Mayo Clinic, 200 1st St SW, Rochester, MN 55905; e-mail: madhavan.ajay@mayo.edu

- Indicates open access to non-subscribers at www.ajnr.org

http://dx.doi.org/10.3174/ajnr.A6309
The goal of this review was to summarize common entities with imaging findings related to the Valsalva or similar physiologic maneuvers, accompanied by case examples (Table 2). Most cases had either a documented clinical history consistent with acute or chronic repetitive use of the Valsalva maneuver or were used to demonstrate how the Valsalva maneuver can be used during imaging to accentuate findings in a diagnostically beneficial way. A minority of cases had an uncertain-but-suspected clinical history of repetitive Valsalva maneuvers. These were included as classic examples of Valsalva-related pathology.

\section{VALSALVA-RELATED CASES BY ANATOMIC LOCATION}

\section{Neck: Spontaneous Pneumomediastinum}

Pneumomediastinum is a well-recognized condition commonly resulting from esophageal or airway trauma. ${ }^{2}$ It is especially pertinent to neuroradiologists in the emergency setting because the findings may be initially seen on neck imaging as air dissects cranially from the superior mediastinum. Valsalva behaviors are among the most common causes of spontaneous pneumomediastinum. Overall, studies on pneumomediastinum have shown coughing, vomiting, drug inhalation, and physical activity to be among the most frequent inciting events. ${ }^{3}$ For example, pneumomediastinum can occur due to barotrauma when users attempt inspiration through a high-resistance smoking apparatus, which causes an increase in alveolar air volume, a decrease in perialveolar pressure, and rupture due to the induced pressure gradient. ${ }^{4}$ A similar phenomenon can occur with cocaine inhalation. In this case, pressure changes due to inhalation and chronic ischemic necrosis of the pharynx secondary to cocaine abuse lead to pharyngeal perforation and pneumomediastinum. Although less common, pneumomediastinum has also been 
Table 1: Net physiologic effects during the Valsalva maneuver

\begin{tabular}{ll}
\hline \multicolumn{1}{c}{ Pressure Changes } & \multicolumn{1}{c}{ Cardiovascular Effects } \\
\hline Increased intrathoracic pressure & Decreased thoracic venous return \\
Increased extrathoracic airway pressure & Distention of extrathoracic venous system \\
Increased middle ear pressure & Decreased stroke volume \\
Increased intracranial pressure & Decreased cardiac output \\
Opening of the Eustachian tube & Peripheral vascular constriction \\
\hline
\end{tabular}

Table 2: Imaging findings associated with the Valsalva maneuver

\begin{tabular}{lll}
\hline \multicolumn{1}{c}{ Neck } & \multicolumn{1}{c}{ Skull Base/Face } & \multicolumn{1}{c}{ Orbit/Head } \\
\hline Jugular phlebectasia & $\begin{array}{l}\text { Nontraumatic orbital floor } \\
\text { fracture } \\
\text { Pneumoparotid }\end{array}$ & Orbital varix \\
$\begin{array}{l}\text { Laryngocele } \\
\text { Spontaneous } \\
\text { pneumomediastinum }\end{array}$ & $\begin{array}{l}\text { Hyperpneumatization of the } \\
\text { skull base }\end{array}$ & $\begin{array}{l}\text { Transient global amnesia } \\
\text { Spontaneous } \\
\text { pneumocephalus }\end{array}$ \\
\hline
\end{tabular}

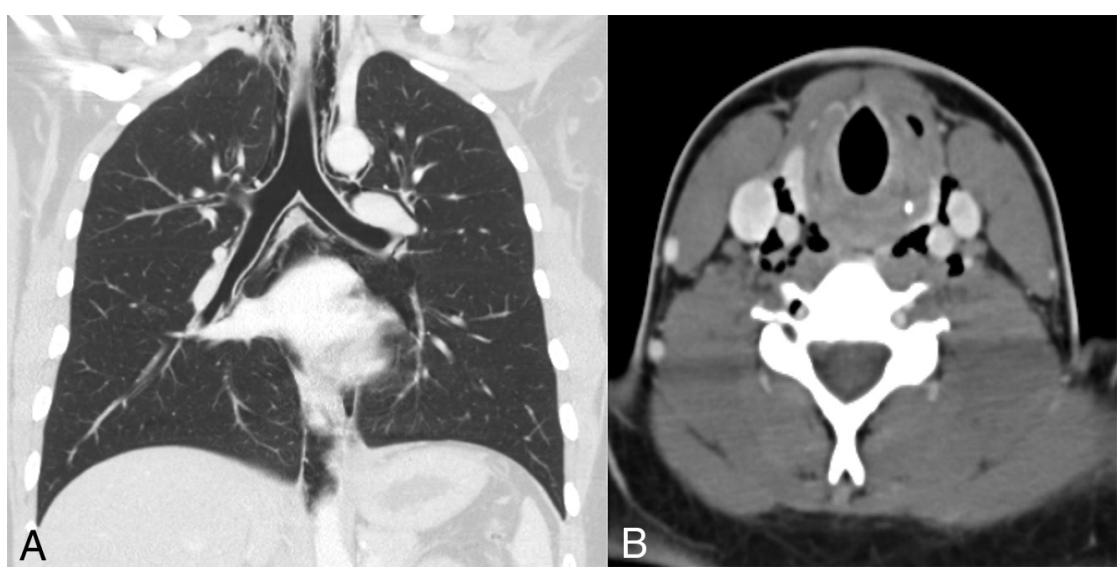

FIG 1. Spontaneous pneumomediastinum. A 19-year-old man with a history of cyclic vomiting syndrome presented to the emergency department after several bouts of severe vomiting with subsequent neck and chest pain. Chest $(A)$ and neck $(B)$ CT images show pneumomediastinum with air dissecting superiorly into both carotid spaces. An esophagram (not shown) demonstrated no evidence of esophageal perforation. The patient was observed for 3 days and discharged uneventfully.

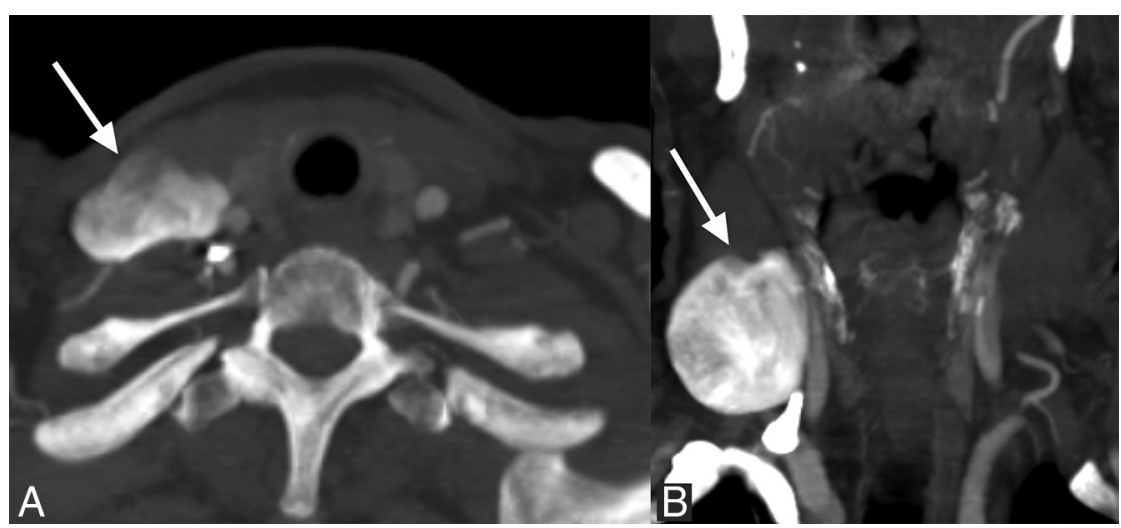

FIG 2. Jugular phlebectasia. A 72-year-old woman with headaches had a neck CTA performed to evaluate vascular disease. Axial $(A)$ and coronal $(B)$ CTA images show a large right jugular venous aneurysm (arrows). This was deemed to be benign without need for treatment. syndrome), a rare condition of severe repeated bouts of vomiting in daily long-term users of marijuana, may cause pneumomediastinum by increasing intra-alveolar pressure (Fig 1).

Pneumomediastinum will slowly resolve as air is resorbed, provided that the underlying cause is reversed. The diagnosis is often made with a chest radiograph, though CT and an esophagram can help define the extent of the abnormality and suggest a cause.

\section{Neck: Jugular Phlebectasia}

While it is very common to have asymmetry in the size of the internal jugular veins, there are uncommon reports of focal aneurysmal dilation of the jugular vein. Jugular phlebectasia is typically an incidental and benign finding but can present with neck pain or cosmetic concerns (Fig 2). This is often accentuated by straining or the Valsalva maneuver (Fig 3). While many of these cases present during childhood, this phenomenon has also been reported in adults. CT, sonography, and MR imaging can all be used to establish this diagnosis, but the use of the Valsalva maneuver is critical in inducing maximum dilation of the jugular vein. Treatment is not required if the patient is asymptomatic, ${ }^{7}$ but surgery has been used in some cases due to symptoms or for cosmetic indications. ${ }^{8}$

\section{Neck: Laryngocele}

Laryngoceles are air-filled dilations of the saccule of the laryngeal ventricle. Internal laryngoceles are confined to the ventricle, while external laryngoceles herniate beyond the thyrohyoid membrane. Laryngoceles are often asymptomatic and found incidentally at imaging (Fig 4A). ${ }^{9}$ Laryngoceles usually contain air and communicate with the lumen of the larynx; however, if obstructed, they may fill with mucus (Fig 4B). External laryngoceles may be more visible and can present as a neck mass. Internal laryngoceles, when symptomatic, can contribute to

previously reported with more benign Valsalva behaviors involving the airway, such as repetitively blowing into a bottle. ${ }^{5,6}$

Repetitive vomiting can also cause pneumomediastinum. For instance, cyclic vomiting syndrome (cannabinoid hyperemesis

1988 Madhavan Dec 2019 www.ajnr.org airway dysfunction such as hoarseness, coughing, dysphonia, or, less commonly, airway compromise. Laryngoceles are associated with Valsalva-related maneuvers. For example, chronic cough and occupations such as glassblowing can cause 
laryngoceles. Additionally, laryngoceles have been observed to enlarge in real-time with the Valsalva maneuver, which could be used to increase diagnostic certainty in unclear cases. ${ }^{9}$ In some cases, an etiology for laryngoceles may not be found. ${ }^{10}$ Because these are usually incidental, the role of imaging is often to exclude a malignant cause, such as laryngeal cancer causing a

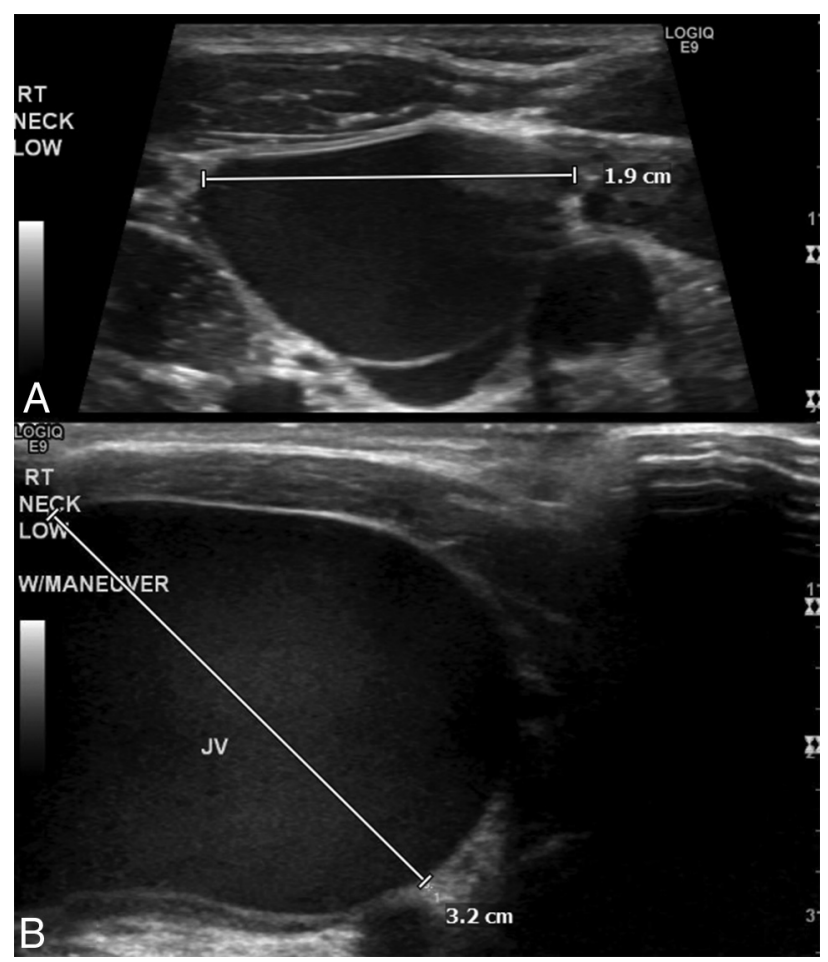

FIG 3. Inducible jugular phlebectasia. A 3-year-old boy presented with intermittent right-neck swelling. Sonographic images of the right neck with $(A)$ and without $(B)$ the use of the Valsalva maneuver show significant enlargement of the right internal jugular vein with Valsalva. After additional work-up to exclude any associated cardiovascular or genetic abnormality, the family was reassured that this was consistent with benign jugular phlebectasia.

secondary laryngocele. Simple excision can be performed for symptomatic cases. ${ }^{11}$

\section{Skull Base/Face: Periorbital Emphysema and Nontraumatic Orbital Floor Fracture}

Periorbital emphysema, often in the setting of blowout fractures of the orbit, is commonly seen in trauma. However, several cases of periorbital emphysema and even nontraumatic orbital fractures have been reported. These have been reported to occur with activities that cause increased intranasal pressure often related to forceful Valsalva maneuvers and include weight-lifting, pressure changes from airplane travel or free diving, and even forceful nose-blowing (Fig 5). In addition, some of these have occurred in the setting of chronic paranasal sinus disease, which has been hypothesized to weaken the orbital floor, making these individuals more susceptible to nontraumatic pathologic fractures. ${ }^{12}$ Treatment is similar to that of traumatic cases and depends on the presence of surgical abnormalities, such as entrapment, compartment syndrome, or persistent diplopia. If no surgical treatment is required, patients are educated to avoid any activities that raise intranasal pressure.

\section{Skull Base/Face: Pneumoparotid}

The term "pneumoparotid" indicates the presence of air within the parotid gland parenchyma, which may extend from forced air through the parotid duct. This may occur with an intraoral pressure increase (eg, blowing up a balloon, playing the trumpet, or with mask anesthesia), which causes air to reflux through the Stenson duct. Pneumoparotid is more likely to occur in patients with compromised natural protective mechanisms. For example, dilation of the Stenson duct, masseter hypertrophy, or buccinator muscle weakness can predispose to pneumoparotid by altering the anatomy of the mucosa normally sealing the duct entrance. ${ }^{13}$

Acute cases can occur in the setting of dental procedures using air-powered cleaning devices that rapidly increase intraoral pressure up to 20 -fold above normal. ${ }^{14}$ Chronic or recurrent cases often occur in occupational set-

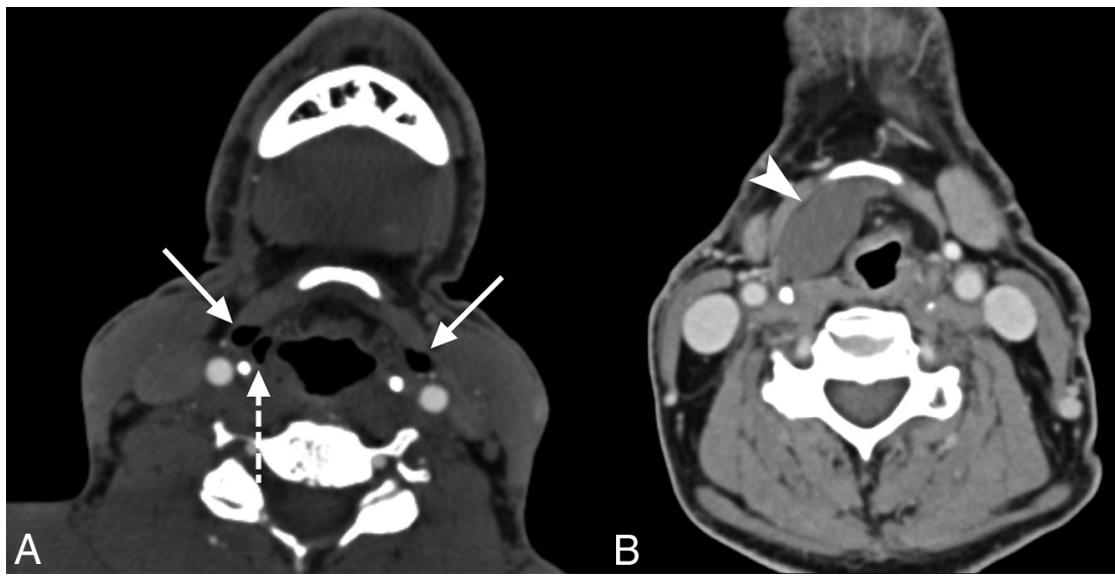

FIG 4. Laryngocele. A 54-year-old with recent viral upper respiratory infection underwent a contrast-enhanced neck CT. Axial contrast images from this patient show mixed internal and external laryngoceles (A, solid and dashed arrows, respectively). Axial contrast-enhanced CT in an asymptomatic 69-year-old (B) shows a fluid-filled internal laryngocele (arrowhead), which was subsequently resected to confirm the diagnosis. tings such as glassblowing or wind instrument playing. Nonoccupational causes include cystic fibrosis, obstructive pulmonary disease, or other diseases that lead to a chronic cough. ${ }^{15}$ Additionally, pneumoparotid can be seen in patients with repetitive psychosocial-related Valsalva behaviors (Fig 6). Patients may be misdiagnosed with parotitis because they will appear to have swelling and pain localized to the parotid region. In some cases, pneumoparotid can be clinically distinguished from parotitis by the presence of crepitus with external palpation of the gland. Most pneumoparotid cases will have concomitant infection/inflammation due to the abundant oral flora refluxing into 


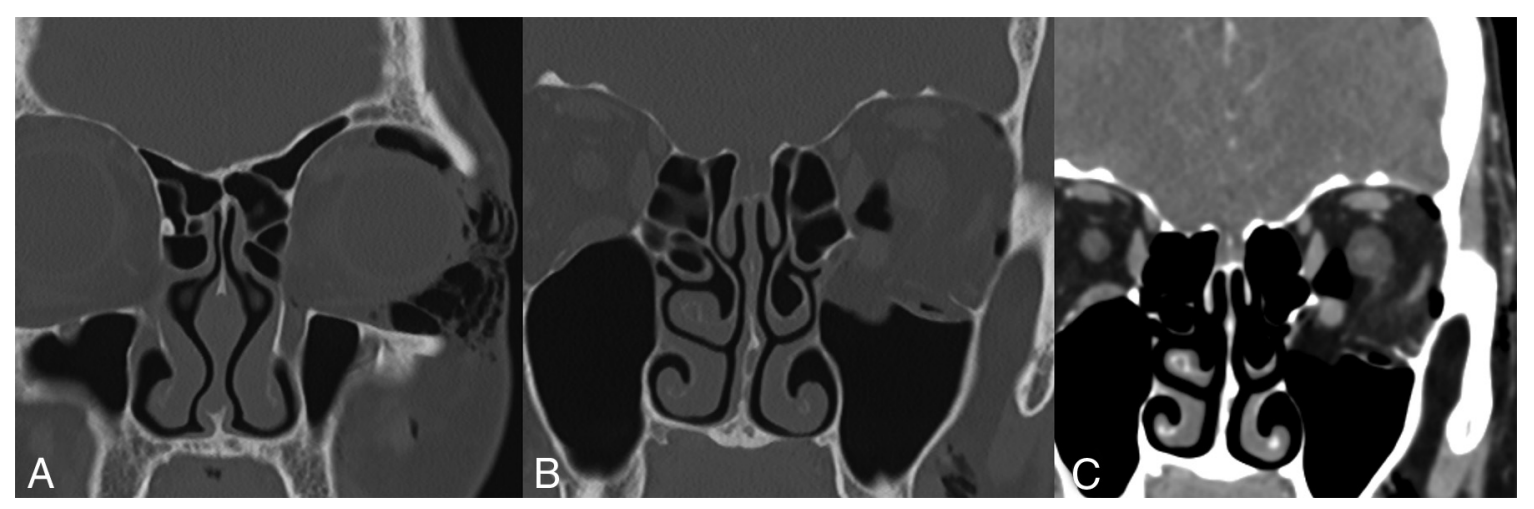

FIG 5. Spontaneous orbital floor fracture. A 58-year-old woman with chronic sinusitis who presented with sudden left periorbital swelling that started after forcefully blowing her nose. Coronal noncontrast CT images with bone $(A$ and $B)$ and soft-tissue $(C)$ windows demonstrate an open-door-type left orbital floor fracture and orbital/periorbital emphysema. After ophthalmology consultation, which excluded any evidence of orbital muscle entrapment or compartment syndrome, she was discharged with a short course of antibiotics without incident.

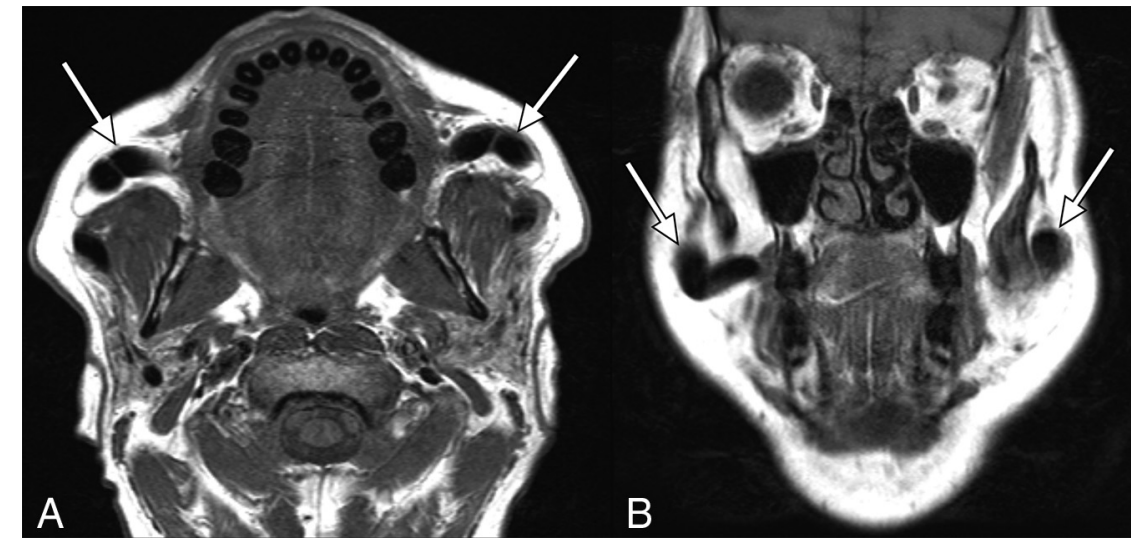

FIG 6. Pneumoparotid. A 57-year-old man was referred to the Ear, Nose and Throat department for chronic bilateral parotid swelling and pain, having been previously treated with antibiotics for parotitis with no symptom improvement. The patient reported periodically massaging his parotid glands, which expressed bubbly saliva into his mouth and temporarily alleviated his symptoms. Axial T1-weighted noncontrast axial $(A)$ and coronal $(B)$ MR images demonstrate marked dilation of the parotid ducts bilaterally (arrows). On further questioning, the patient recalled that he had been chronically pursing his lips and putting pressure inside his mouth. He was advised to avoid this in the future and to return should his symptoms worsen.

the duct. The main role of cross-sectional imaging is to identify air in the parotid gland/duct and evaluate the extent of disease. Moreover, imaging may identify dissection of air into the parapharyngeal or retropharyngeal spaces, which can occur in cases of a particularly high-pressure pneumoparotid. ${ }^{16}$ Treatment is usually conservative, with patient education being key.

\section{Skull Base/Face: Hyperpneumatization of the Skull Base}

Pneumatization of the skull base and paranasal sinuses occurs in 3 stages: infant (younger than 2 years), transitional (24 years), and adult. Pneumatization can be developmentally exuberant, which is considered a normal variant. ${ }^{17}$ However, hyperpneumatization and pneumatization of unusual locations like the craniocervical junction have also been associated with repetitive Valsalva maneuvers. It is thought that during the Valsalva maneuver, a ball valve mechanism occurs wherein air is forced into the Eustachian tube and subsequently trapped (Fig 7). ${ }^{18}$ Coughing and high-altitude travel can lead to hyperpneumatization as well, putatively through the same mechanism. Skull base hyperpneumatization through these mechanisms is not entirely benign. The high pressure associated with this process can induce bone ischemia and lead to microfractures. ${ }^{19}$ Additionally, hyperpneumatization has been reported to extend to the craniocervical junction and epidural space. ${ }^{20}$ This likely occurs due to venous transmission of air and the presence of microfractures, respectively. Fortunately, hyperpneumatization and epidural air have been shown to be reversible, sometimes by simply instructing patients to avoid repetitive Valsalva maneuvers. However, more aggressive treatment such as tympanic pressure equalization via ventilation tubes can be necessary. Patients with skull base hyperpneumatization should be advised to avoid contact sports due to the increased risk of traumatic fracture. ${ }^{19}$

It is important to document the presence of skull base hyperpneumatization. Skull base surgical approaches may be altered if important neurovascular structures may have unexpected anatomy due to extended areas of dehiscence. Extreme skull base pneumatization also carries an elevated risk of CSF leak during a skull base or intracranial operation. Last, hyperpneumatization must be clearly differentiated from pathologic osseous lucency. ${ }^{17}$

\section{Orbit: Orbital Varix}

Orbital varices can be classified as primary (congenital/idiopathic) or secondary, often due to upstream high-flow vascular lesions such as intracranial arteriovenous malformations, carotid cavernous fistulas, or dural arteriovenous fistulas. Overall, they are quite rare and make up a minority of orbital lesions (approximately $1 \%-2 \%)$. They typically present in the second or third decade affecting males and females equally. Most exhibit 
characteristic distension with maneuvers that increase venous pressure (eg, coughing, breath-holding) because they have a large communication with the venous system. This is termed "stress proptosis," which is dramatic protrusion of the eye with any Valsalva-type maneuver. This ability to enlarge with a Valsalva maneuver is key to imaging and confirming the diagnosis (Fig 8). Occasionally, the venous communication is minimal, and these

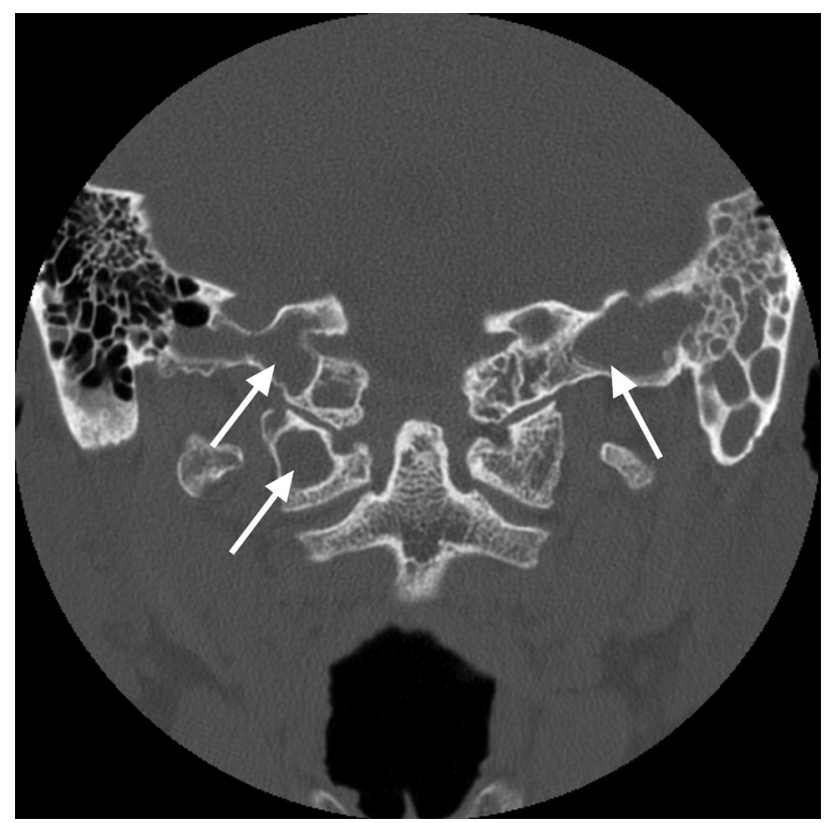

FIG 7. Hyperpneumatization of the skull base. A 47-year-old woman was referred to the Ear, Nose and Throat department for chronic allergies that caused her to habitually clear her throat. Coronal noncontrast CT of the skull base shows hyperpneumatization of the temporal bones, $\mathrm{Cl}$ ring, and dens, which are secondarily opacified (arrows). cases can present with acute onset of painful proptosis relating to thrombosis and hemorrhage. ${ }^{21}$ Intervention, either surgical or endovascular, is usually reserved for symptomatic cases resulting from mass effect or thrombosis. ${ }^{22}$

\section{Cranial: Transient Global Amnesia}

Transient global amnesia is defined as an episode of anterograde or retrograde amnesia lasting $<24$ hours. It has been reported to be associated with diffusion restriction in the CA1 subfield of the hippocampus. There have been several previously reported cases in association with the Valsalva maneuver and a variety of physical activities. ${ }^{23,24}$ It is possible that transient global amnesia occurs due to retrograde flow in the internal jugular vein induced by the Valsalva maneuver, leading to temporary cerebral venous congestion. Others have theorized that paradoxical emboli precipitated by the Valsalva maneuver might lead to transient global amnesia, though patients with transient global amnesia have not been shown to have a higher incidence of right-to-left shunts. ${ }^{24}$ Ultimately, the exact pathogenesis of transient global amnesia is uncertain, but its correlation with the Valsalva maneuver is quite diagnostically useful. We have seen hippocampal infarcts associated with transient global amnesia after weight-lifting (Fig 9A, -B) and associated with sexual intercourse (Fig 9C, $-D$ ).

\section{Cranial: Spontaneous Nontraumatic Pneumocephalus}

Pneumocephalus refers to the abnormal presence of intracranial air, which is usually due to trauma or an operation. However, rare cases of spontaneous pneumocephalus have been reported in the literature, typically related to the Valsalva maneuver, cranial defects, infection, or neoplasm. ${ }^{25}$ Sometimes, predisposing factors such as sinus osteomas can be seen in association with spontaneous nontraumatic pneumocephalus (Fig 10). Osteomas may lead to osseous erosion, providing a conduit for air to enter the skull from paranasal sinuses or air cells. The air then may become trapped through a ball valve mechanism as the cranial defect is sealed by the arachnoid membrane. $^{26}$ Regardless of the cause, pneumocephalus is important to recognize because it can cause headache or sensations of increased pressure. In cases of unexpected clinical decompensation, particularly in postoperative patients, mass effect on the brain from pneumocephalus (tension pneumocephalus) is an important consideration that requires prompt surgical attention.

\section{CONCLUSIONS}

The unique physiologic changes that occur from the Valsalva maneuver can result in a variety of head and neck abnormalities with characteristic imaging findings. Additionally,
FIG 8. Orbital varix. A 70-year-old woman who presented due to an orbital mass incidentally discovered on an outside brain MR imaging. Axial ( $A$ and $C$ ) and coronal $(B$ and $D) C T$ images of the orbits without $(A$ and $B$ ) and with $(C$ and $D)$ a Valsalva maneuver demonstrate inducible enlargement of a lobular structure in the right orbit (arrows), consistent with a varix. The patient subsequently reported right-eye fullness when bending over. No additional treatment was pursued. 


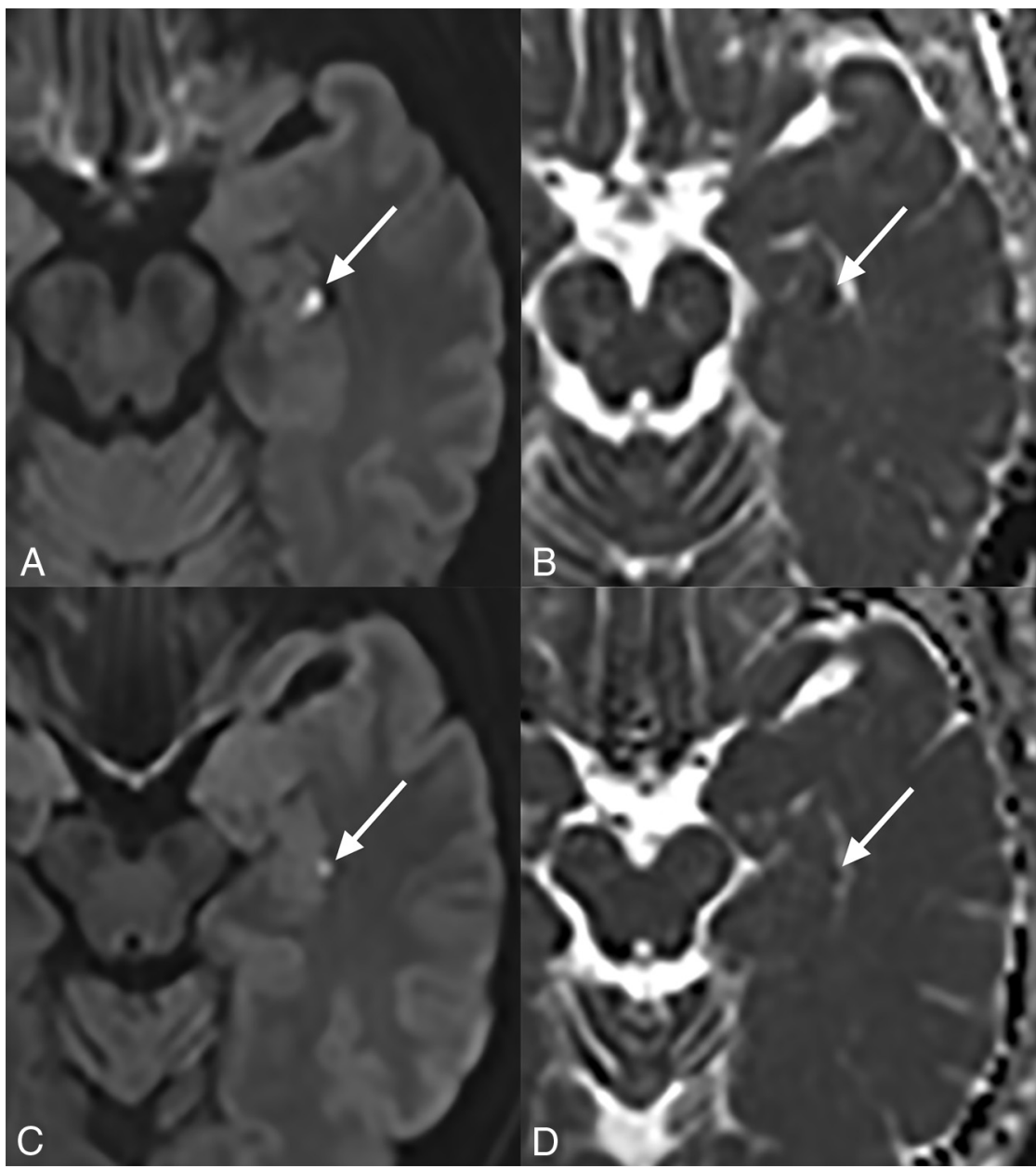

FIG 9. Transient global amnesia. A 58-year-old man who presented with retrograde amnesia. He had gone to the gym and completed his usual workout routine including bench-pressing earlier that day. When he returned home, he had no memory of being at the gym despite having recorded his exercises in his daily workout log. An axial diffusion-weighted MR image $(A)$ and a corresponding $A D C$ map (B) show a focus of diffusion restriction in the left hippocampus (arrows). The same findings (arrows) are demonstrated on axial diffusion-weighted (C) and ADC (D) images from a 57-yearold man with mixed retrograde/anterograde amnesia following sexual intercourse.

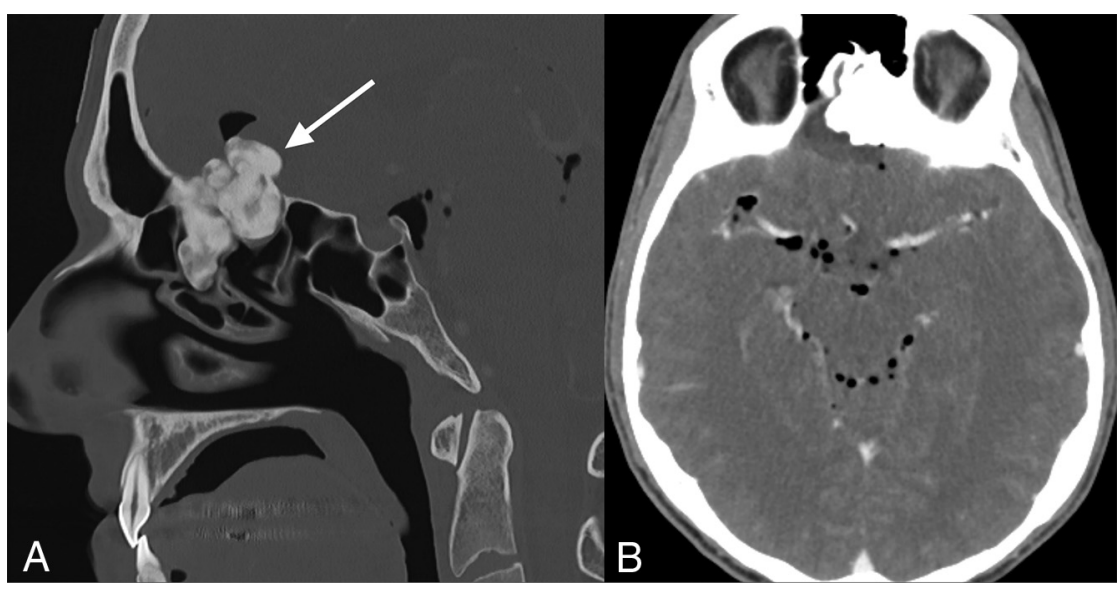

FIG 10. Spontaneous pneumocephalus. A 27-year-old ex-Marine with a recent history of clear rhinorrhea for 1 week presented with acute, severe head pressure that started during weight-lifting. Sagittal CT $(A)$ shows a giant osteoma extending superiorly from the ethmoid air cells (arrow). There is extensive subarachnoid pneumocephalus ( $A$ and $B)$. the Valsalva maneuver can be intentionally used during imaging to aid in diagnosing various conditions. Identification of Valsalva-related imaging abnormalities can help prompt clinicians to elicit relevant history from patients. Thus, it is important to recognize these findings, carefully correlate them with relevant clinical history, and communicate with referring clinicians if additional history must be obtained. It is also helpful to have knowledge of lesions commonly encountered on routine imaging that predispose patients to the Valsalva or other pressure gradientrelated effects.

Some of the entities presented are incidental findings and do not necessarily have immediate clinical significance. However, it is important to recognize these findings as well to avoid incorrect diagnoses or unnecessary additional work-up, especially true in cases in which use of the Valsalva maneuver during imaging supports the benignity of a lesion. Recognition of these cases will help clinicians make clinically relevant diagnoses and prevent undue treatment of benign, incidental findings.

Disclosures: Ajay A. Madhaven-RELATED: Support for Travel to Meetings for the Study or Other Purposes: Mayo Clinic, Comments: travel/conference reimbursement to present work at the American Society of Head and Neck Radiology 2018 Annual Meeting in Savannah, Georgia.

\section{ACKNOWLEDGMENTS}

The authors acknowledge the assistance of Sonia Watson, $\mathrm{PhD}$, in editing the manuscript.

\section{REFERENCES}

1. Luster EA, Baumgartner N, Adams WC, et al. Effects of hypovolemia and posture on responses to the Valsalva maneuver. Aviat Space Environ Med 1996;67:308-13 Medline

2. Vianello A, et al. Spontaneous pneumomediastinum complicating severe acute asthma exacerbation in adult patients. J Asthma 20171-77 CrossRef Medline

3. Sahni S, Verma S, Grullon J, et al. Spontaneous pneumomediastinum: time for consensus. $N \mathrm{Am} \mathrm{J} \mathrm{Med} \mathrm{Sci}$ 2013;5:460-64 CrossRef Medline

4. Weiss ZF, Gore S, Foderaro A. Pneumomediastinum in marijuana users: 
a retrospective review of $\mathbf{1 4}$ cases. BMJ Open Respir Res 2019;6: e000391 CrossRef Medline

5. Swe T, Naing AT, Lixon A, et al. Spontaneous pneumomediastinum, pneumoretroperitoneum, and cervicofacial subcutaneous emphysema after repeatedly and forcefully blowing into a bottle. J Community Hosp Intern Med Perspect 2016;6:33361 CrossRef Medline

6. Pittman JA, Pounsford JC. Spontaneous pneumomediastinum and Ecstasy abuse. J Accid Emerg Med 1997;14:335-36 CrossRef Medline

7. Bora MK. Internal jugular phlebectasia: diagnosis by ultrasonography, Doppler and contrast CT. J Clin Diagn Res 2013;7:1194-96 CrossRef Medline

8. $\mathrm{Hu} \mathrm{X}, \mathrm{Li} \mathrm{J}, \mathrm{Hu} \mathrm{T}$, et al. Congenital jugular vein phlebectasia. Am J Otolaryngol 2005;26:172-74 CrossRef Medline

9. Upile T, Jerjes W, Sipaul F, et al. Laryngocele: a rare complication of surgical tracheostomy. BMC Surg 2006;6:14 CrossRef Medline

10. Spinosi MC, Mezzedimi C, Monciatti G, et al. Internal laryngocele: unusual onset in a 91-year-old female patient. Sultan Qaboos Univ Med J 2018;18:e104-06 CrossRef Medline

11. Glazer HS, Mauro MA, Aronberg DJ, et al. Computed tomography of laryngoceles. AJR Am J Roentgenol 1983;140:549-52 CrossRef Medline

12. Sandhu RS, Shah AD. Nontraumatic orbital floor fracture after nose-blowing. Radiology Case Rep 2016;11:1-3 CrossRef Medline

13. Markowitz-Spence L, Brodsky L, Seidell G, et al. Self-induced pneumoparotitis in an adolescent: report of a case and review of the literature. Int J Pediatr Otorhinolaryngol 1987;14:113-21 CrossRef Medline

14. Martin-Granizo R, et al. Pneumoparotid in childhood: report of two cases. J Oral Maxillofac Surg 1999;57:1468-71 CrossRef Medline

15. Brodie HA, Chole RA. Recurrent pneumosialadenitis: a case presentation and new surgical intervention. Otolaryngol Head Neck Surg 1988;98:350-53 CrossRef Medline
16. Luaces R, Ferreras J, Patiño B, et al. Pneumoparotid: a case report and review of the literature. J Oral Maxillofac Surg 2008;66:362-65 CrossRef Medline

17. Wemhoff M, Jain R, Rock J. Hyperpneumatization of the skull base: case report. Neurosurgery 2012;70:E789-93 discussion E793-94. CrossRef Medline

18. Quigley AJ, Shannon H. Craniocervical pneumatization. J Radiol Case Rep 2013;7:27-33 CrossRef Medline

19. Francies O, Morley S, Beale T. Skull base and craniocervical bone pneumatisation: two case reports of differing presentations and a review of the literature. J Radiol Case Rep 2017;11:1-10 CrossRef Medline

20. Littrell LA, Leutmer PH, Lane JI, et al. Progressive calvarial and upper cervical pneumatization associated with habitual Valsalva maneuver in a 70-year-old man. AJNR Am J Neuroradiol 2004; 25:491-93 Medline

21. Smoker WR, Gentry LR, Yee NK, et al. Vascular lesions of the orbit: more than meets the eye. Radiographics 2008;28:185-204; quiz 325 CrossRef Medline

22. Weill A, Cognard C, Castaings L, et al. Embolization of an orbital varix after surgical exposure. AJNR Am J Neuroradiol 1998;19:92123 Medline

23. Mariaca AF, Valdueza JM, Gaebel C, et al. Simultaneous transient global amnesia and right MCA stroke after Valsalva manoeuvre. BMJ Case Rep 2017 CrossRef Medline

24. Owen D, Paranandi B, Sivakumar R, et al. Classical diseases revisited: transient global amnesia. Postgrad Med J 2007;83:236-39 CrossRef Medline

25. Pishbin E, Azarfardian N, Salarirad M, et al. Spontaneous nontraumatic pneumocephalus: a case report. Iran Red Crescent Med J 2015;17:e23920 CrossRef Medline

26. Umredkar AB, Disawal A, Anand A, et al. Frontal sinus osteoma with pneumocephalus: a rare cause of progressive hemiparesis. Indian J Radiol Imaging 2017;27:46-48 CrossRef Medline 